\title{
Dynamics of Household Role Performance and the Culture of Child Health Production in Igbo-Ora, Southwestern Nigeria
}

\author{
Kabiru K. Salami \\ University of Ibadan \\ Ayodele S. Jegede \\ University of Ibadan \\ Frederick O. Oshiname \\ University of Ibadan
}

Studies about production of health for children have mainly concentrated on the behavior of one or two key household members compared to the dynamics in households involving three or more members. Health production refers to the process of directing available knowledge, skills, and resources towards ensuring, maintaining, and sustaining the health of the members. This cross-sectional design study explored how the dynamics of household structure and members' roles influence the process of health production in a rural Nigerian community. An interviewer-moderated questionnaire was administered through a panel survey approach in 576 households. Twelve in-depth interviews and eight group discussion sessions were also conducted in Igbo-Ora, Southwestern Nigeria. Twenty-two roles identified from qualitative narratives, grouped into social interaction, material supports, safe environment, and physical health care supports categories, were ranked on a score of performance by household members. The mean household size was 5.4. Malaria, acute respiratory infection, and diarrhea were reported for children in $41.8 \%$ households. Mothers recognized and took action on child's illnesses, while fathers made payment for treatment than other household members. Household decisions on child's wellbeing focus more on treatment (84.4\%) than preventive (7.3\%) actions, while final decision resides more in the fathers' (58.3\%) compared to the mothers' (15.8\%) authorities. Mothers scored the highest points in all the role categories, the fathers scored points next to the mothers in material support, and safe-environment roles, while the children's older siblings scored points next to the mothers on social interaction and caring roles. Health is produced in Igbo-Ora through the consciousness of growth monitoring, safe environment, and hygiene practice.

Keywords: child health, culture of child rearing, growth monitoring, reproductive roles, production of health 


\section{Introduction}

Childrearing is a major reproductive role of households globally. Household members' involvement plays an important role in young children's cognitive and social development (Weiss, Caspe, \& Lopez, 2006). One area where this role is obvious is health production for children under age 5 . This is especially the case in Sub-Saharan Africa, where child mortality is high and access to health care services is limited (Liu et al., 2015). Production within the context of household (i.e., household production) refers to those activities aimed at satisfying the various immediate and future consumption needs of household members (Turon, 2016). Household production of health, which is a critical part of the general household production, refers to the process of directing available knowledge, skills, and resources towards ensuring, maintaining, and sustaining the health of the members. Household production of health places households at the center of the health improvement process (Dawson, 1991). Nevertheless, that does not mean that households control all the resources required to respond to health problems or that households are the only important unit of analysis. Conditions such as abject poverty and inadequate health and community services place a limitation on how much control a household can exercise on the process of health production.

Studies that focused on household health production for children in Africa and particularly Nigeria have concentrated on the behavior of one or two key members, primarily mothers, and sometimes fathers and other caregivers such as grandmothers. One such study by Brieger, Watts, and Yacoob (1989) showed that a mother is usually a part of the core group in the management of guinea worm disease and that her own illness can have devastating effects on her children's health (Adebami, Oyedeji, Owa, \& Oyelami, 2007). Such disabling diseases can reduce her capacity to be actively involved in health production of others in the household.

McLain (1989) emphasized the need to amplify the "ignored" roles of women as household health practitioners, if the dynamics of the household production of health are to be understood. Recent studies on parental care seeking and utilization of maternal and child health services have documented the behavior of the mothers and the dynamic response of the fathers as determining factors in baby delivery and survival in Nigeria (Abdulkadir \& Abdulkadir, 2016; Salami, Dumbili, \& Ezeah, 2013), Ethiopia (Abate \& Belachew, 2017), and in other low- and middle-income countries (Banke-Thomas, Banke-Thomas, \& Ameh, 2017). Studies on household decision making in the care of children with febrile conditions have also found that parents differ in role and contribution (Olaogun, Brieger, Ayoola, Obianjuwa, \& Adebayo, 2005). Most studies recognize that the household unit in the Nigeria context is often dynamic, large and diverse, often consisting of core members and various temporary or part-time participants. However, those studies have not examined how that construct as a dynamic system contributes to child health status in a communal-driven culture where upbringing is a collective responsibility of the parents and the entire household (Albert, Awe, Herault \& Omitoogun, 1995; Amos, 2013; Russell, 2004).

Hong, Banta, and Betancourt (2006) established that production of child health includes the roles meant to raise and ensure survival of children - the process which, in turn, ensures sustenance of procreation (DeLoache \& Gottlieb, 2000; Wacira, Hill, McCall, \& Kroeger, 2007). Features of production of health were extended to include maintenance of a neat home environment (Pan American Health Organization, 1997) and supervision and protection of children from mishap by older siblings, cousins, other children or relatives (Bledsoe \& Isiugo-Abanihe, 1989; DeLoache \& Gottlieb, 2000; United Nations Children's Fund, 2013). Social and economic factors also have 
implications for household health production since households are part of the social and economic environment (Abdulkadir \& Abdulkadir, 2016; Turon, 2016). It is therefore considered inadequate to analyze household production independent of the environment (Banke-Thomas et al., 2017; Sanglimsuwan, 2012; Turon. 2016).

Writings and debates by indigenous scholars on gender discourse (Oyewumi, 1997), food preparation and storage (Ehiri et al., 2001), and those on food crisis and food insecurity (National Population Commission \& ICF International, 2014) indicate that household involvement is among the sources of considerable negative impact on infants, young children, and women's health. Studies on African countries like Kenya have also reported a negative role of household involvement in the treatment of injuries of any kind (Nordberg, Kimani, \& Diwan, 2000). Household involvement is so influential that in India, neonates' parents' lack of satisfaction in intensive care unit prompted the adoption of a family-centered care that prioritizes greater parental satisfaction (Sankar, Batra, Saroha, \& Sadiza, 2017). Also, studies conducted in Nigeria on twins reported both negative and positive reactions from household members as having a significant influence on the health outcomes of twins and their mothers (Asindi, Young, Etuk, \& Udo, 1993; Salami, Brieger, \& Olutayo, 2003).

Many studies have reported that caregivers adopted diverse care-seeking behaviors for different child ages among different populations in Nigeria. Those behaviors include utilizing a range of care options in managing child illness (Ogunlesi \& Olanrewaju, 2010; Ogunlesi \& Ogunlesi, 2012).

Nevertheless, Nigeria continues to report one of the highest rates of neonatal deaths in Africa (Ezeh et al., 2014) with the effect of the loss being felt by household members. Besides socioeconomic and biodemographic characteristics at the household level, involvement at the community level was also found associated with under-age-5 mortality in Nigeria (Akinyemi, Adedini, \& Odimegwu, 2017). These critical involvements are enacted within the sequential pattern of care-seeking identified by Brown (1998), which suggests that care for an illness is initially provided at home by household members. Even a hospital-based study on care-seeking for child illness observed that children under 1 year of age were more likely to be treated at hospital and also more likely than older children to be treated at home with drugs (Ogunlesi \& Olanrewaju, 2010). Olson (1994) admonished that

In order to clarify the processes involved in the household production of health, the knowledge, skills, remedies, and pathways of illness treatment and health maintenance must be examined, and this includes the contributions not just of female domestic healers, but of spouses and other household and non-household members as well. (p. 147)

These are relative processes of production of health for members of households. However, attention has not been given to these sociocultural dimensions of health production in childcare, which is important to a holistic appraisal in Nigeria health care system. As a result of the complex nature of the actors and factors that are involved in household health production and care seeking, researchers in this area have often considered mixed method approaches for their heuristic value (Abdulkadir \& Abdulkadir, 2016). As Johnson, Onwuegbuzie, and Turner (2007) maintained, mixed-methods approaches are appropriate for generating a holistic perspective required for a broad understanding of a phenomenon. By considering the dynamics of household structure, member roles and process of production of health in a rural Nigerian community, this mixed-method study documents how household members combined their knowledge, resources, and behavioral norms and patterns with available technologies, services, information, and skills to restore, maintain, and promote the health of preschool-aged children in the rural community of Igbo-Ora, Southwestern Nigeria. 


\section{Materials and Method}

This study was conducted in Igbo-Ora, a community with an estimated population of 66,612 persons (National Population Commission, 2000), situated on longitude $71^{\circ} 2^{\prime} \mathrm{N}$ and latitude $30^{\circ} 4^{\prime} \mathrm{E}$ (Watson \& Wareham, 1963). Igbo-Ora is about $100 \mathrm{~km}$ west of Ibadan, the Oyo State capital, and about $40 \mathrm{~km}$ northwest of Abeokuta, the Ogun State capital. Residents of Igbo-Ora are predominantly Yoruba, living in extended family housing clusters called agbole (compound). A compound in Igbo-Ora is a conglomeration of houses in a particular geographical portion of land. It is a circularly structured form of many houses where people of the same genealogical background live. With predominantly a farming population, Igbo-Ora has agriculture as the mainstay of its local economy. The majority of Igbo-Ora people are Muslims and Christians while few people are devotees of traditional religion.

The present exploratory study utilized descriptive cross-sectional survey designs with mixed methods and considered household as the unit of analysis. Twelve in-depth interviews (IDIs) were conducted among key persons in the community. The interviews involved an equal number of men and women. In addition to the interviews, eight focus group discussions (FGDs), two each among fathers, mothers, grandfathers, and grandmothers, were conducted. While the IDIs were conducted to get insights into household member's expected roles in health production, FGDs were designed to identify the community practices and attitudes/perceptions involved in the production of health for members. Also, 576 copies of a pretested, interviewer-moderated questionnaire were administered through a panel survey approach in 576 households. A mixed-methods design was adopted in order to achieve a holistic result. Narratives from IDIs and FGDs were analysed deductively and inductively. The results of the analyses informed the content of the questionnaire used for the survey which adopted the Household Panel Survey (HHPS) approach (Olaogun et al., 2005; Russell, 2004; Seekings, 2003). The HHPS approach, as used in this study, brought together (a) the mother of the index child, (b) the father of the child, and (c) one other person identified among the household for giving care and attention to the child. The instruments used in this study were pretested in a nearby community, analysed and the lessons learnt were utilized when designing the final versions of the instruments and during data collection.

Furthermore, a systematic approach was adopted to visit all the 288 compounds in the Igbo-Ora community and at least two children under age 5 (a male and a female match) were sampled in each compound, giving rise to 576 children. Availability of children under age 5 , and the availability of potential members of HHPS were considered in selecting households that participated in the study. Where more than one household was qualified for inclusion in the study, the final decision on inclusion was made through balloting and with preference given to a biological child. Also, where more than one biological child qualified, the youngest was considered in order to reduce the risk of recall bias for the HHPS members. Consents of all participants of IDIs and FGDs and HHPS members were sought before the interviews. In a household where either one or two members of the panel was absent for the panel survey, a repeat visit was made at least twice.

The data collected were checked and edited daily and later coded and entered into the computer for analysis using Epi Info Version 6.04a, a free program developed and provided through the U.S. Centers for Disease Control and Prevention (Atlanta, GA), for quantitative data. TextBase Beta Software was used to analyse the qualitative data. TextBase Beta software was developed by Bo Summerlund and distributed by Qualitative Research Management (Desert Hot Springs, CA). The 
Authors received a copy of the software from the World Health Organization through a previous research project. The textual data generated from the interviews and discussions were subjected to deductive content analysis that focused on identifying key themes.

On returns from the field, narratives from IDIs and FGDs were transcribed verbatim and a thematic analysis was undertaken (Braun \& Clarke, 2006) using the framework approach (Spencer, Ritchie, \& O'Connor, 2003). The framework approach allows for both deductive and inductive theme identification which can be explained through two phases consisting of five main steps: (a) familiarization with the data, (b) development of a thematic/coding framework, and (c) indexing/coding data in the data management phase using TextBase Beta, and (d) charting and (e) mapping the data in the data explanation phase. These two phases enhance theory-driven and datadriven analysis (Braun \& Clarke, 2006; Fereday \& Muir-Cochrane, 2006).

As noted by Braun and Clarke (2006), thematic analysis is relevant when investigating an underresearched area or while working with participants whose views on the topic are not known. This approach was followed with collaborative analysis by the authors to ensure analytical rigor (Cornish, Gillespie \& Zittoun, 2014). A number of queries were conducted, including a word frequency query to gain an insight into the words most frequently used by the participants and how this could help in identifying the patterns within the whole data set. At the end, the nodes were exported to a word document and read many times to arrive at the patterns of meaning from the key themes. Results generated from both qualitative and quantitative data were synthesized and presented taking into account the frequency distribution of role performance. The content analysis was also substantiated by direct textual quotations.

\section{Results}

\section{The Ethnography of Household Panel}

A total of 1,728 household members from 288 compounds in the Igbo-Ora community participated in this survey. The HHPS was administered to 576 mothers $\left(M_{\text {age }}=29.2\right.$ years $), 576$ fathers $\left(M_{\text {age }}=36.5\right.$ years), and 576 "other members" ( $n=123$ male, $n=453$ female; $M_{\text {age }}=25.4$ years). Table 1 provides information about sex, educational level, occupation, marital status, and religious affiliation of the panel members. There were more mothers with monogamous (65.6\%) than polygamous (34.4\%) marital type. Similarly, 375 (65.1\%) and 201 (34.9\%) fathers indicated that they were monogamous and polygamous, respectively.

Data were collected on the children under age 5 to document their behavior and understand their developmental milestones. The child data indicate that a total of 576 ( $n=288$ male, $n=288$ female) children under age 5 ( $M_{\text {age }}=32.02$ months) were surveyed in 288 compounds. The birth orders of the children ranged from first $(24.3 \%)$ to eighth $\left(0.2 \% ; M_{\text {birth_order }}=2.6\right)$. About a quarter $(28.6 \%)$ of the children were second-order born, and overall sibling interval was found to range between 12 and 59 months ( $M_{\text {interval }}=52.2$ months). Only a mean of 4.4 households lived under same building, categorized as blood related only (69.1\%), blood related with tenants (20.5\%), and tenants only (10.4\%). The majority ( $n=454,78.8 \%$ ) of the children had immunization cards. 
Table 1. Sociodemographics of Household Panel Members

\begin{tabular}{|c|c|c|c|c|c|c|}
\hline \multirow[b]{3}{*}{ Sociodemographics } & \multicolumn{6}{|c|}{ Household Panel Members } \\
\hline & \multicolumn{2}{|c|}{ Father } & \multicolumn{2}{|c|}{ Mother } & \multicolumn{2}{|c|}{ Other } \\
\hline & $n$ & $\%$ & $n$ & $\%$ & $n$ & $\%$ \\
\hline \multicolumn{7}{|l|}{ Sex } \\
\hline Male & 576 & 100 & - & - & 123 & 21.3 \\
\hline Female & - & - & 576 & 100 & 453 & 78.7 \\
\hline \multicolumn{7}{|l|}{ Educational level } \\
\hline No formal education & 108 & 18.7 & 99 & 17.2 & 183 & 31.8 \\
\hline Primary & 208 & 36.1 & 286 & 49.7 & 248 & 43.1 \\
\hline Junior secondary & 29 & 5.0 & 48 & 8.3 & 53 & 9.2 \\
\hline Senior secondary & 202 & 35.1 & 122 & 21.2 & 80 & 13.9 \\
\hline Tertiary & 29 & 5.0 & 21 & 3.7 & 12 & 2.0 \\
\hline \multicolumn{7}{|l|}{ Marital status } \\
\hline Married & 576 & 100 & 576 & 100 & 226 & 39.2 \\
\hline Single & - & - & - & - & 348 & 60.4 \\
\hline Divorce & - & - & - & - & 2 & 0.4 \\
\hline \multicolumn{7}{|l|}{ Religion } \\
\hline Christianity & 173 & 30.0 & 183 & 31.8 & 165 & 28.6 \\
\hline Islam & 401 & 69.6 & 393 & 68.2 & 411 & 71.4 \\
\hline \multicolumn{7}{|l|}{ Occupation } \\
\hline Farming & 11 & 1.9 & 79 & 13.2 & 29 & 5.0 \\
\hline Trading & 432 & 74.9 & 90 & 15.3 & 162 & 28.2 \\
\hline Civil service & 13 & 2.3 & 34 & 5.9 & 3 & 0.5 \\
\hline Housewife & 13 & 2.3 & - & - & 3 & 0.5 \\
\hline Artisan & 83 & 14.5 & 200 & 34.5 & 27 & 4.5 \\
\hline Students & 5 & 0.9 & 8 & 1.4 & 304 & 52.8 \\
\hline Clergy & 1 & 0.2 & 9 & 1.6 & 1 & 0.2 \\
\hline Clerical & 2 & 0.3 & 1 & 0.2 & - & - \\
\hline Driving & 1 & 0.2 & 142 & 24.7 & 2 & 0.3 \\
\hline Herbalist & 一 & - & 4 & 0.7 & 1 & 0.2 \\
\hline Health workers/nurse & 3 & 0.5 & - & - & 1 & 0.2 \\
\hline Apprentice & 3 & 0.5 & - & - & 3 & 0.5 \\
\hline Politician & - & - & 2 & 0.3 & 8 & 1.4 \\
\hline
\end{tabular}

Data collection on the household started with a census of the members: 3,118 members across 576 households. Table 2 provides information on the residence status and dynamics of household members using the following indicators: full residence (eating and sleeping in the household), nonfull residence (eating from the household but sleeping elsewhere; sleeping in the household but eating elsewhere) and nonresidence (living outside the community but visiting his/her household occasionally). In most ( $n=565 ; 98.1 \%)$ of the households surveyed, participants actually slept in the households the previous night before the survey. The majority $(n=2,888 ; 92.6 \%)$ of the household members were full residents. Nonfull residents included 98 (3.1\%) who took their meals in their households but slept elsewhere in the community and $15(0.5 \%)$ who slept in the household but took their meals somewhere else in the community. 
Table 2. Household Membership Composition: Residence Status and Dynamics of the Members

\begin{tabular}{|c|c|c|c|c|c|}
\hline \multirow[b]{3}{*}{$\begin{array}{l}\text { Members of } \\
\text { Household }\end{array}$} & \multicolumn{4}{|c|}{ Resident Status, $n(\%)$} & \multirow[b]{3}{*}{ Total $N$} \\
\hline & \multirow[b]{2}{*}{$\begin{array}{c}\text { Full } \\
\text { Resident }\end{array}$} & \multicolumn{2}{|c|}{ Nonfull Resident } & \multirow[b]{2}{*}{$\begin{array}{c}\text { Not } \\
\text { Resident }\end{array}$} & \\
\hline & & $\begin{array}{c}\text { Only Eats } \\
\text { There }\end{array}$ & $\begin{array}{c}\text { Only Sleeps } \\
\text { There }\end{array}$ & & \\
\hline Father & $532(92.4 \%)$ & $19(3.3 \%)$ & $3(0.5 \%)$ & $22(3.8 \%)$ & 576 \\
\hline Mother & $564(97.9 \%)$ & $6(1.0 \%)$ & $0(0.0 \%)$ & $6(1.0 \%)$ & 576 \\
\hline Sibling & $1,552(93.7 \%)$ & $40(2.4 \%)$ & $2(0.1 \%)$ & $63(3.8 \%)$ & 1,657 \\
\hline Cowife & $13(54.2 \%)$ & $5(20.8 \%)$ & $3(12.5 \%)$ & $3(12.5 \%)$ & 24 \\
\hline $\begin{array}{l}\text { Son/Daughter-in- } \\
\text { law }\end{array}$ & $39(79.6 \%)$ & $3(6.1 \%)$ & $0(0.0 \%)$ & $7(14.3 \%)$ & 49 \\
\hline Other child & $2(40.0 \%)$ & $1(20.0 \%)$ & $1(20.0 \%)$ & $1(20.0 \%)$ & 5 \\
\hline Grandfather & $9(75.0 \%)$ & $0(0.0 \%)$ & $1(8.3 \%)$ & $2(16.7 \%)$ & 12 \\
\hline Grandmother & $101(81.5 \%)$ & $12(9.7 \%)$ & $3(2.4 \%)$ & $8(6.5 \%)$ & 124 \\
\hline Other relative & $57(87.7 \%)$ & $6(9.2 \%)$ & $0(0.0 \%)$ & $2(3.1 \%)$ & 65 \\
\hline Nonrelative & $19(63.3 \%)$ & $6(20.0 \%)$ & $2(6.7 \%)$ & $3(10.0 \%)$ & 30 \\
\hline Total & $2,888(92.6 \%)$ & $98(3.1 \%)$ & $15(0.5 \%)$ & 117 (3.8\%) & 3,118 \\
\hline Average & 5.0 & 0.2 & 0.0 & 0.2 & 5.4 \\
\hline
\end{tabular}

Nonresident status accounted for 117 (3.8\%) members. Specifically, 92.4\% and 97.9\% of fathers and mothers, respectively, were full residents; $3.3 \%$ and $1.0 \%$ of fathers and mothers, respectively, ate from the household but slept elsewhere; $0.5 \%$ fathers slept there only; and 3.8\% fathers and 1.0\% mothers reportedly lived outside the study community. Children accounted for a larger population in the surveyed household with the majority $(n=1,552,93.7 \%)$ of them being full residents, 63 (3.8\%) living outside the community, 40 (2.4\%) eating in the household but sleeping elsewhere in the community, and two (0.1\%) children sleeping only but eating elsewhere in the community. Table 2 shows that the mean household membership size was 5.4 with 5.0 being full residents, 0.2 only eating in the household, and 0.2 living outside but visiting their household regularly.

The content analysis of (observation of gestures and nonverbal communication during HHPS) field notes clearly indicated the third members of HHPS as check and balances for the fathers and mothers in the discussion of role performance. Observations showed that consensuses were reached easily for roles played by either of the parents or other household members. In addition, clarifications were sought from the third member when roles overlapped, in order to identify the actual member that played the roles.

\section{The Dynamics of Role Performance Behavior}

Household composition drives membership roles and influences role differentials in child health production among members. Twenty-two needs that were attributed to upbringing and supporting the children under age 5 emerged from qualitative study. Concerns about the nature of the environment where a child is raised topped the discussion list of the respondents. The environment that reportedly influences the health of individuals is, however, also symmetrically influenced by "safe environment and hygiene practice," as reported in the group discussion of mothers. The environment is also noted to have influences on how a child relates with his or her peers. As "safe 
environment" and "hygienic practices" of the parents and other household members were identified as some determinants of good health outcome of a child, regular monitoring was also emphasized to protect a child from contracting diseases or to protect a child against dangerous objects around the household.

Members of the fathers' groups were concerned about the household environment where a child resides: "Children should be nightly monitored against dangerous objects; they should not be allowed to play around near unhygienic places." A discussant from a mothers' group also emphasized the need for a "culture of child monitoring" where a child is allowed to socialize with his or her peers but with an adequate guide by someone. This is considered very important at the crawling milestone in child development: "Apart from the zeal that we make environment clean, we still monitor them around not to eat dirt from the earth, not to go near dangerous things like fire, broken bottles or even climbing trees."

The high consciousness of growth monitoring observed was indicative of its importance to the mothers who perceived possession of good growth by a child as a sign of healthiness. Mothers also felt that growth is a constant variable experienced by everyone, but they clearly stated that a child with little or minimum care and attention has the tendency to experience a "slow growth." According to the discussants, slow growth is a sign of unhealthiness. For a smooth growth process, good hygiene practice, balanced nutrition, access to immunization, and a safe environment free from communicable diseases were emphasized in a mother's discussion group: “. . consumption of (a) complete diet such as those that we are encouraged to give our children at hospitals, completing our children immunization, and always remember to make our compounds tidy are more important in making our children live healthy."

Beyond the "care and monitoring" roles attributed to biological parents is the recognition that joint care by other members of the household should be given to a child. The discussants perceived that the "monitoring" of a child should not be left to parents alone. Rather, it should also be the concern of other members of the household. A father emphasized that "It is the responsibility of any [household] member to prevent a child from mishaps or from dangerous things/activities."

Discussants in a grandfather group even expressed that a line should not be drawn as to who provides what in child upbringing roles, because

roles on enhancing and ensuring healthy living for children and/or growing well have no borderline in terms of who performs what. All roles, all supports, and all cares are performed jointly by every member of the household without waiting for the [biological] parents.

Another grandfather emphasized that Af'owow'ewol'owo fi mo (washing hands with both hands ensures clean hands) and proposed for a child a joint-care provided by all members. A reflection on awareness of "perceived possible effects" of a member's illness on the "expenditure of the family" was clearly reflected in the response of the fathers in their discussion group. Hence, the call for immediate intervention of household members in the care of a sick child:

The outcome of a person's bad action doesn't affect the person alone but extends to neighbours; therefore, attention to illness of a child should not be left to the child's parents alone. Rather, other members of the household should also take good care of the child by taking him/her to hospital. 
Role differentials by gender bear on the welfare of children as exemplified in a fathers' group discussion:

The fathers play much significant roles because they are the head of the household; they fund foods, shelters and other basic things needed by household members. The mothers prepare foods and do some domestic works. In case there is any dispute at home, the grandfathers settle it. Even the siblings help their parents. All these joint roles help in the care for small children.

\section{Household Members' Role Differentials on Children Under Age 5}

The present study examined role differential and level of involvement/performance by household members as shown in Table 3. Content analysis of narratives from qualitative aspect of the study also highlighted the specific roles performed by individual members in the household on children under age 5. The participants indicated that in some cases, these roles overlap, while some are specific to people according to their positions in the household.

In the qualitative narratives, 22 things were considered to be what a child needs to survive and live healthily. They were grouped into four categories in the household survey to identify the members of the household who provided them regularly for the child. Table 3 shows that the four categories include providing material support, providing physical care, social interaction and provision of safe environment. Table 3 also shows that the roles played by household members are dynamic. For instance, it was observed that even though the fathers and the mothers play the most significant role in child survival, their roles overlap with those of other household members. While the results did not indicate no complete role performance from either of the parents, they showed that certain roles were performed by specific members of the household more than others. For instance, fathers and mothers were the major providers of material support for children under age 5. Even though such supports were also provided by other members, in most cases, mothers provided the major supports compared to fathers and others. Specifically, clothes were provided mostly by the fathers (91.0\%) and mothers (88.5\%), followed by the grandmothers (14.1\%), and maternal relatives (12.2\%). Good food for a child was mostly provided by the mothers $(94.1 \%)$ and fathers $(47.6 \%)$. Whenever the child was ill, herbs were provided by more of fathers $(65.5 \%)$ than the mothers $(51.4 \%)$ and the grandmothers (13.9\%), while drug and other medicines were provided mostly by the mothers (91.7\%) than the fathers (15.5\%) and others in the household. Money was mostly provided by the fathers (67.4\%), almost twice that of the mothers (34.9\%). The mothers (84.0\%) bought toys/playing materials for children followed by the fathers (37.0\%) and the older child (12.5\%).

Furthermore, most of the care provided for children under age 5 was from the mothers, older children, the fathers, and the grandmothers, as shown in Table 3. The results indicate that nutritional care in the form of breastfeeding was exclusively provided by the mothers (97.4\%). Also, observing child immunization schedule (97.4\%), back-carrying the child most of time (95.5\%), and bathing the child (95.3\%) were performed by the mothers. In the provision of care such as "carrying the child most of time, carrying the child, bathing the child and prevent child from mishap," the older child was found next to mothers. Among those who "noticed if child is sick" and "take child to hospital for treatment," fathers came next to mothers. Grandmothers also played the roles of "backing the child" (i.e., back-carrying), "carrying the child," "bathing the child," and "preventing the 
child from mishaps." Other household members also provided care for the children under age 5 but were not prominent, as shown in Table 3.

The mothers also met most of the social interaction needs of the children under age 5 . Nevertheless, the social interaction needs of the children met by the fathers, older children, and the grandmothers were higher than the other supports they gave to the child. More so, putting the child to bed was done mostly by the mothers (89.8\%), followed by older children (53.6\%), the fathers $(34.2 \%)$, and the grandmothers (18.9\%). Besides, the mothers and the older children (36.1\%) also teach them lessons. It was discovered also that the fathers, mothers, older children, and grandmothers all sought information pertaining to the child. But a safe environment was provided mainly by fathers and mothers. The results show that whenever the environment was bushy, the fathers $(72.2 \%)$ cleared it while the mothers (90.6\%) clean/swept the environment because of their children. 
Table 3. Child Needs and Household Supports on Needs

\begin{tabular}{|c|c|c|c|c|c|c|c|c|c|}
\hline \multirow[b]{2}{*}{ Needs of Child } & \multicolumn{9}{|c|}{ Household Members } \\
\hline & Father & Mother & $\begin{array}{l}\text { Older } \\
\text { Child } \\
\end{array}$ & Grandfather & Grandmother & Cowife & $\begin{array}{l}\text { House } \\
\text { help }\end{array}$ & $\begin{array}{l}\text { Maternal } \\
\text { Relative }\end{array}$ & $\begin{array}{c}\text { Paternal } \\
\text { relative }\end{array}$ \\
\hline \multicolumn{10}{|l|}{ Material support } \\
\hline Provides clothes for the child & 91.0 & 88.5 & 4.3 & 1.7 & 14.1 & 0.5 & 1.2 & 12.2 & 9.2 \\
\hline Provides good food for the child & 47.6 & 94.1 & 9.5 & 0.3 & 7.8 & 0.7 & 1.0 & 2.4 & 1.2 \\
\hline Provides herbs for the child & 65.5 & 51.4 & 5.6 & 8.2 & 13.9 & 0.5 & 1.0 & 2.8 & 1.2 \\
\hline $\begin{array}{l}\text { Provides drugs and other medicine when the child } \\
\text { is ill }\end{array}$ & 15.5 & 91.7 & 8.5 & 0.5 & 5.2 & 0.7 & 0.9 & 2.1 & 1.2 \\
\hline Provides money to parents to support the child & 67.4 & 34.9 & 2.4 & 4.7 & 7.3 & 0.3 & 0.2 & 2.1 & 1.2 \\
\hline Buys toys for the child & 37.0 & 84.0 & 12.5 & 0.7 & 4.2 & 0.7 & 0.5 & 4.3 & 4.3 \\
\hline \multicolumn{10}{|l|}{ Physical healthcare } \\
\hline Backs the child most of time & 5.6 & 95.5 & 35.6 & 0.5 & 21.2 & 2.4 & 2.4 & 6.6 & 3.6 \\
\hline Carries the child most of time & 34.2 & 93.8 & 48.1 & 1.7 & 20.8 & 2.8 & 3.3 & 7.6 & 5.2 \\
\hline Gives milk/breastmilk to the child & 5.4 & 97.4 & 2.6 & 0.2 & 3.5 & 0.2 & 0.5 & 0.7 & 0.2 \\
\hline Bathes the child & 7.1 & 95.3 & 24.7 & 0.3 & 11.3 & 1.2 & 0.9 & 3.0 & 3.0 \\
\hline Notices if the child is sick & 21.5 & 90.8 & 5.0 & 0.3 & 9.2 & 1.0 & 0.7 & 1.0 & 0.9 \\
\hline $\begin{array}{l}\text { Takes the child to hospital for treatment during } \\
\text { illness }\end{array}$ & 11.1 & 93.4 & 2.1 & 0.2 & 3.1 & 0 & 0 & 0.2 & 0.3 \\
\hline Provides toilet care for the child & 4.7 & 67.4 & 8.3 & 0.2 & 3.3 & 1.2 & 1.2 & 1.2 & 2.1 \\
\hline $\begin{array}{l}\text { Prevents the child from mishaps and dangerous } \\
\text { things around the house }\end{array}$ & 24.0 & 93.9 & 28.1 & 1.4 & 10.6 & 1.6 & 1.0 & 3.0 & 2.8 \\
\hline Takes the child for immunization & 4.9 & 97.4 & 2.8 & 0 & 1.2 & 0.3 & 0.3 & 0.3 & 0.3 \\
\hline Sleeps in the place with the child at night & 32.8 & 93.9 & 16.3 & 0.5 & 5.9 & 0.2 & 0 & 1.4 & 0.5 \\
\hline \multicolumn{10}{|l|}{ Social interaction } \\
\hline Plays with the child regularly & 34.2 & 89.8 & 53.6 & 1.7 & 18.9 & 2.6 & 4.0 & 5.6 & 4.9 \\
\hline Checks on the child/greets the child regularly & 41.5 & 85.6 & 22.0 & 3.5 & 26.4 & 1.9 & 4.3 & 5.6 & 4.7 \\
\hline Teaches the child lessons & 15.6 & 69.6 & 36.1 & 0 & 4.0 & 0.7 & 3.1 & 3.0 & 2.4 \\
\hline Source information on the child & 38.5 & 52.3 & 10.1 & 4.2 & 14.8 & 2.1 & 1.2 & 4.2 & 3.5 \\
\hline \multicolumn{10}{|l|}{ Safe environment } \\
\hline Clears bushes around houses because of the child & 72.2 & 35.4 & 9.9 & 0.9 & 1.6 & 0.3 & 2.6 & 1.7 & 1.7 \\
\hline Cleans dirty environment because of the child & 11.3 & 90.6 & 17.5 & 0 & 4.0 & 1.6 & 2.8 & 3.0 & 1.9 \\
\hline
\end{tabular}




\section{Household Members' Roles Performance on Children Under Age 5}

The household members' presence, closeness to/familiarity with a child, and consistent attention to the child's needs determine the extent of childcare provided by household members. Monitoring of children against mishaps and dangerous objects was a concern of all household members. Mothers and older siblings reportedly monitored and prevented child from mishaps. While mothers solely offered breastfeeding, both mothers and the child's siblings reportedly guided the child for treatment during illness. Playing with the children and protecting them from dangerous things are roles attributed to child's siblings. Also, "provision of balanced diets," "regular breastfeeding," "hygiene practice," and "protection against dangerous things" are all roles reportedly played by the mothers. Young fathers affirmed that the intensity of preventive and treatment roles played by the mothers and the child's older sibling is higher than theirs. A member of the group underscores this:

I, as the father, believe that the mother and the older children have more roles to play on maintaining good health for the child, because they are always around with him and they live more closely to the child. If they notice any problem on the child, they have to attend to him on time. In fact, the mother has more roles and she must always look after the child.

Monitoring and preventive roles were identified as social roles attributed mostly to a mother or a child's sibling. In the Yoruba parlance where patriarchal style recognizes the father as the head of the family/household, the resources expended on the household are attributed to the father/husband; hence, members of the household do not only perform preventive roles on child's safety and care, but also protect the interest of the father as the source of resources for the household. According to a mother,

The mother watches and monitors her child's movement closely. In case the child is going to a dangerous object, it is the responsibility of the mother or the older children to prevent the child. In case a man has more than one wife, other wives also have responsibilities to protect the child because if the child is sick, it is definite that the husband would divert most of the household resources to the child's ill health; this would definitely affect other expenses for other children and their mothers.

The nonregular presence of the father at home may limit his childcare contribution. However, whenever the father is available, he is culturally expected to support the mother in the "caring-job" for the child. By supporting the mother in taking care of the child, in the long run, the father gains recognition from the child, as explained by a mother: "The father, whenever he is around, has the responsibility to play with the child because Agb'omo jo l'omo $n$ m'oju (a child recognizes whoever relates/plays with him/her)."

\section{Household Members' Roles Performance in Illness Experience}

The extent of role performance in a child's health was measured through household members' involvement in child's illness history of malaria, diarrhea, and acute respiratory infection (ARI). With the previous 4 weeks before the survey used as timeframe, slightly less than half $(241 ; 41.8 \%)$ of the households reported child's illness experience. Malaria (61.8\%) was reportedly higher than ARI (56.4\%) and diarrhea (31.1\%). 
Table 4 shows that the mothers were the first to recognize that a child was suffering from diarrhea (66.7\%), followed by the fathers (32.0\%) and the grandfathers $(1.3 \%)$ of the children surveyed. In the same manner, treatment actions were taken by the mothers in $70.7 \%$ households, by the fathers in $21.3 \%$ households, and by grandfathers in two (2.7\%) households. In one (1.3\%) household each, the child's siblings and grandmother acted. Treatment fees were paid mostly by the fathers (70.7\%) and the mothers (20.0\%) in the households. A malaria episode was reportedly experienced by $149(61.8 \%)$ children with mothers being the first to recognize the symptoms in 104 (69.8\%) households, followed by the fathers in 37 (24.8\%) households and grandmothers in only three (2.0\%) households.

Table 4 indicates that treatment actions were taken mostly by the mothers in malaria episodic households than other members. Although the fathers' involvement in treatment actions was about a third $(22.8 \%)$ of the mothers' $(68.5 \%)$, costs were mostly paid by the fathers $(71.8 \%)$ compared to the mothers (21.5\%) and grandparents (2.0\%). Seven (4.7\%) households did not disclose the bearer of cost of treatment during the illness of their children.

Table 4. Household Members' Roles in Illness Management

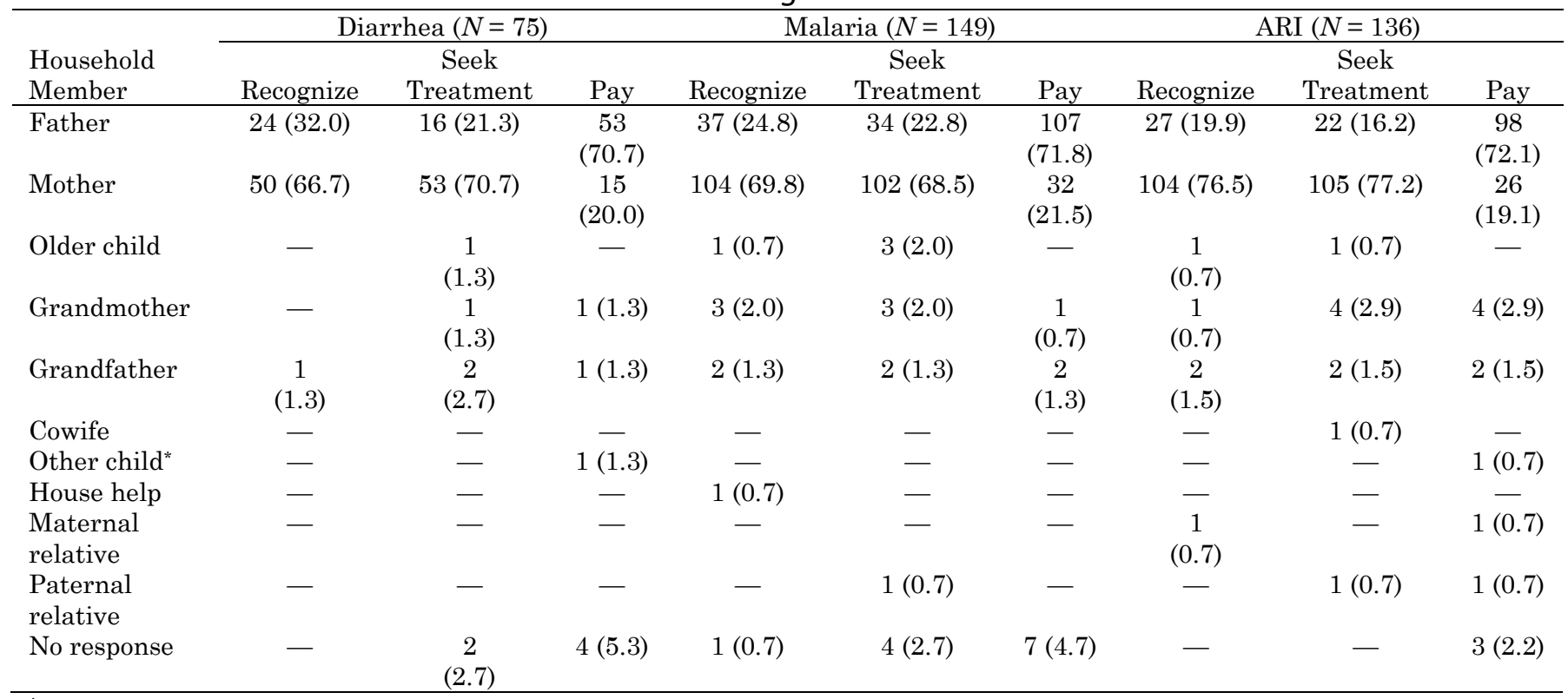

* Stepchild or grandchild.

\section{Household Members' Roles Performance in Illness Prevention}

The measures put in place by the households for preventing diarrhea, malaria, and ARI among the children were reported. Overall, children were prevented against diarrhea in $336(58.3 \%)$ households through the "use of clean cup" in 218 (64.9\%) households, and through "regular hand washing" and "use of clean spoon" in 36 (10.6\%) households for each. Other measures taken were "use of window net to prevent flies" in 11 (3.3\%) households, "taking the child to hospital for regular check-up" in 10 (3.0\%) households, "boiling water" in 11 (3.3\%) households, and "using drugs at home" and "home herbs" in seven (2.1\%) households each. Household members recognized, sought, and paid for the preventive activities for the three childhood diseases considered in this study. Need for appropriate prevention of diarrhea was recognized by the mothers in many $(65.8 \%)$ households or by the fathers 
in about one quarter (25.6\%) of households, compared to grandfathers in three (0.9\%) households and child's siblings in two (0.6\%) households. Table 5 shows that preventive measures were taken by more mothers (in $66.7 \%$ households) than the fathers (in $20.2 \%$ households) and other household members. Payment for preventive measures cost the households between N10.00 and N3,000.00 with mean cost of N155.09, with the exemption of 125 households without expenses on prevention. Table 5 also shows that the cost incurred on preventive measures was paid mostly by the fathers (in $50.9 \%$ households) than the mothers (in $12.8 \%$ households) and other household members. Table 5 contains detail information about prevention of diarrhea, malaria, and ARI by household members.

Table 5. Household Members' Roles in Childhood Illness Prevention

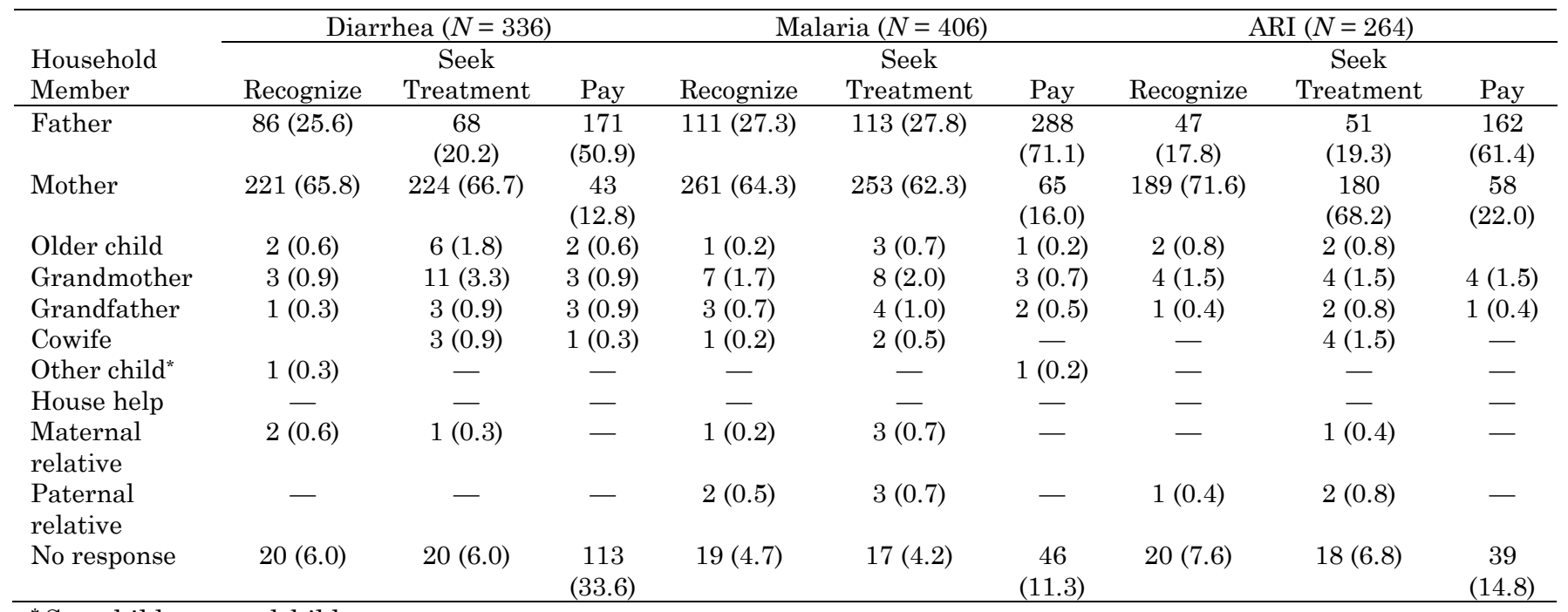

* Stepchild or grandchild.

Clearly, in the present study, the data indicate the peculiarity of role differentials as a determinant of the extent of role performance among household members. Even within the same health activity, such as immunizations for children, responses from discussion groups implied the traditional gender role differences: "Fathers and grandparents are expected to remind the mothers on uptake of children for immunization, while the mothers are expected to uptake the children for immunization." One instance drawn from a grandmothers' group noted, "Fathers and grandparents should intimate the mothers to take their children for immunization and the mothers should take their children for immunization." In addition, fathers' expected roles were confirmed in a mothers' group: "the father encourages us to take our children for immunization. Once we are intimated, we must be ready to take the child for immunization."

\section{Household Dynamics on Decision Making and Role Performance}

The decision-making phenomenon isolates gender as an aggregate that presupposes social rather than biological relations as a mode of decision making at the household level. Initial decisions pertaining to treatment of a child were made by the father in 155 (26.9\%) households, the mother in 206 (35.8\%) households, grandparents in 17 (3.0\%) households, and older children in 22 (3.8\%) households. However, HHPS members reported that final decisions on child health matters were made by the fathers. This occurred in more than half (58.3\%) of the households, followed by the 
grandparents in 115 (20.0\%) households, the mothers in 91 (15.8\%) households, and older siblings in 34 (5.9\%) households. Significantly, results indicate that even if a father did not participate in the initial decision-making process on child health matters (as in $26.9 \%$ fathers against $35.8 \%$ mothers), the final decision still resides in the authority of the father (58.3\%) compared to the mothers' (15.8\%). This finding emphasizes the role of gender and social relations in health production decision at the household level. More importantly, a decision is more often made on treatment (84.4\%) than on prevention $(7.3 \%)$.

\section{The Extent of Role Performance on Children Under Age 5 Among Household Members}

Results on specific roles of household members presented in Table 6 and the narratives from the interviews and group discussions indicate clearly that there are role differentials. These provided insight into the extent of involvement by members. For instance, results on household members' role performance on child illness experience, the decision-making process, and child vaccine information identified the extent of role performance at different stages. Table 6 provides summary information on the extent of role performance by household members on children under age 5 . The key role components, as shown in Table 6, are broken into four groups and ranked on a score of 0-4 points for social interaction, 0-6 points for material supports, 0-2 points for safe environment, and 0-10 points for physical health care supports. Household members were rated/scored based on performance of each role in the category. Results in Table 6 indicate that the mothers scored highest points in all the role categories, the fathers scored points next to the mothers in material support and safe environment roles, while the children's older siblings scored points next to the mothers on social interaction and caring roles. Table 6 shows that the regularity of the extent of role performance is a function of individual position in the household.

Table 6. Extent of Role Performance by Household Members on Children Under Age 5

\begin{tabular}{lcccccc}
\hline \multicolumn{1}{c}{ Roles } & \multicolumn{6}{c}{ Household Members $^{\text {a }}$} \\
\hline & & & \multicolumn{5}{c}{ Child's } \\
Variables & Scales & Father & Mother & Sibling & Grandfather & Grandmother \\
\hline Provide social interactions & $0-4$ & 1.3 & 2.8 & 1.5 & 0.4 & 0.9 \\
Provide material support & $0-6$ & 3.2 & 4.4 & 0.4 & 0.1 & 0.5 \\
Provide safe environment & $0-2$ & 0.8 & 1.3 & 0.3 & 0.0 & 0.1 \\
Provide physical health care & $0-10$ & 1.2 & 8.2 & 1.4 & 0.1 & 0.8 \\
\hline
\end{tabular}

a Selected household member categories that are common to most households and who were indicated as performing regular roles by the household panel members.

\section{Ethnography of Factors Associated With Role Performance}

The extent to which "possession of assets and stable jobs" influenced role performance was reinforced by the informants. "Household structure (nuclear or extended)" and "education" were also described as determinants of social role performance in health production by the discussants. The respondents positioned "the possessions" as a factor for obtaining basic things needed such as good nutrition and shelters and for ensuring survival and wellbeing-related activities for children under age 5. Access to assets such as landed property and/or motor cars for commercial purposes to generate funds for members in the household is also positioned as an important determinant. Maintenance of clean 
environment through "regular clearing of surrounding bushes" and "regular refuse disposal" was emphasized as means "to avoid contaminated environment," "prevent breeding of housefly," and "to prevent diseases such as cholera and typhoid fever from attacking children." The importance of education in the ability to read instructions on labels and billboards and in the ability to understand and follow preventive measures on instructional facilities in order to avoid expired drugs, expired foods, and expired drinks was also noted.

\section{Discussion}

The present study has provided insight into the household health production dynamics involving multiplicity of role performance and how these social constructs have impacted the survival and wellbeing of children under age 5 in Igbo-Ora. While this study focused on household, it did not attempt to document a simple story of householding and its members but about the ongoing active participation of members and the intrinsic social dynamics in the household in producing and sustaining the healthiness and wellbeing of children under age 5 (Bernardi et al., 2013). The study has shown that one of the most important institutions in the lives of man (including those with more or less possessions) is the household. The present study shows that the household is a basic unit of society where individuals both cooperate and compete for both resource-sharing and responsibilities (Bloom \& Dawson, 1991; Himmelweit, Santos, Sevilla, \& Sofer, 2013) on members' "development" (including health and wellbeing) and, more importantly, for children under age 5. The kind of competition that evolves in the household (Dawson, 1991), especially on finance (European Commission, 2013), care (Design Council, 2013), recognition (Azuh, Fayomi \& Ajayi, 2015), and payment for and treatment of child illness (Ponthieux, 2017) as indicated in this study, is a healthy one. This is made, remade, and contested in a range of institutional arenas that dynamically produced healthiness and wellbeing for children under age 5. This is one of the global strategies suggested for achieving sustainable development goals (Every Woman Every Child, 2015).

Ethnographically, the community structure described correlates with Bascom's (1969) and Oyewumi's (1997) analyses of social structure in Yoruba land. Qualitative responses showed that indeed families may extend across two or three or even more households, while a household sometimes contains two or more families, as also found by Cherlin (1992), especially in those households where house help or a nonrelative are employed. The current study identified the household as the minimal unit of aggregated social relations which also serves as the fundamental unit of production (Berman, Kendall, \& Bhattacharyya, 1994). This finding correlates with the position of Akinyemi, Chisumpa, and Odimegwu (2016) that the extended family households' arrangement has the ability to enhance agricultural production in providing resources to relations who may have been disadvantaged if they live alone.

Mothers of children under age 5 identified themselves and were identified by other household members as "home keepers" who are responsible for the wellbeing of their children. Even when mothers do not have enough resources, they are willing to undertake considerable risk in order to provide for their children as indicated in this study. In fact, this study reveals that $97.9 \%$ of mothers were fully resident, while $81.5 \%$ grandmothers were fully resident. The full residence status of grandmother indicates their influential role in supporting young mothers either as their daughters or daughters-in-law during pregnancy, childbirth, and throughout the newborn experiences (Partnership for Maternal, Newborn, and Child Health, 2006). However, the proportion of fathers and grandfathers this study found living outside the community could be on sojourn partly for 
economic purposes (Centre for Public Legal Education Alberta, 2014). This raises/increases the extent of their role performance. The same extent of role performance was discussed in SmithGreenaway's (2013) study where it was observed that even mothers with minimum education such as secondary education were more likely to garner financial resources to promote and cater for their child's health care needs and welfare. The father of children under age 5/the husbands of the mothers of children under age 5 were viewed as the "breadwinners" and also as the decision makers on the treatment pathways/patterns for children. Similar findings have been reported in a study where income was reallocated from fathers to mothers in order to increase child's consumption, nutrition, and wellbeing (Himmelweit et al., 2013). Also in a study that documented the impact of health-treatment decision on divided family budgets in Nigeria (Orubuloye, Caldwell, Caldwell, \& Bledsoe, 1991), it was found that most child treatment was paid for by only one person, usually a parent, and that the treatment chosen is determined by the person meeting the cost. Mothers are most likely to pay for minor illnesses, but the father's role becomes more important as the cost rises. Consequently, the patriarchal system in Igbo-Ora, like other Yoruba communities (Azuh et al., 2015), allows the men largely to determine patterns of health seeking including time and where to seek treatment. It has been shown that this is reinforced by the balance of power within the household, which is in favor of men (White, Dynes, Rubardt, Sissoko, \& Stephenson, 2013). For instance, a study by Lawoyin (2001) suggested that greater attention might be given to male children, in terms of getting quality care because of the higher premium placed on male children. However, all the efforts are geared toward producing good health outcome and wellbeing for children in the household.

As the extent of role performance is influenced by the position of each individual in the household, the mother performs more roles in all categories of roles. However, performance of roles does not confer on the mothers more power for decision making. This study shows that even if a father did not participate in the initial decision-making process on child health matters, the final decision still resides in his authority (58.3\%) compared to the mothers (15.8\%), even when her argument is tailored toward severity of an illness. Although the health belief model emphasizes the importance of perceived severity of an illness on care decision-making (Green \& Murphy, 2002), a woman's husband (Ewhrudjakpor, 2008), mother-in-law (Brown, 1998), relatives, neighbors, and other community members were also found influencing care-seeking behaviors and decisions for childhood illness in rural communities. This finding emphasizes the role of gender and social relations in health production decision at household level. More importantly, decision is most often made on treatment (84.4\%) than prevention (7.3\%) at the household level.

The data presented in this study indicated a low literacy level among mothers. Notwithstanding the level of education, the data still indicated a high rate of illness recognition skills and treatment seeking by mothers compared to fathers. This is contrary to findings in northern Nigeria, where mothers with low literacy and households in rural areas had lower recognition of newborn danger signs (Federal Ministry of Health, 2011), while some mothers report not seeking care outside of the home because they felt their child would get better without medication (Marchant, 2013).

\section{Limitations of the Study}

This study presented the reported dynamic roles performed by the participants and those performed by other members of their households, for maintenance of child health and wellbeing in the household. An indirect limitation is that some respondents may have honestly supplied inaccurate 
information about their households, either by painting the picture in a more robust way than they were or making a claim of roles or responsibilities they did not perform. This is the usual limitation of interview surveys that rely on reported responses. However, adoption of a panel approach in the survey reduced such limitation to the bare minimum. This is in addition to the fact that participation in the study was voluntary, adequate information about the study was provided before engaging the participants, and standard ethical steps were implemented in all the phases of the study.

\section{Conclusion}

Because the study indicates that household members' involvement (beyond the parental roles alone) in the care and upbringing of children under age 5 is crucial in Igbo-Ora, household-focused education on prompt health treatment must be accompanied by measures aimed at changing behavior (preventive). The household-focused education should be broadened to encompass issues such as home-based care, women's health rights, the financing of the health care system, and determinants of gender roles in household production of health. These areas could form new research focuses for further studies. While reaching parents with information on child survival strategies is crucial, focused behavior-change programs must also involve other members of the households and utilize their different local knowledge and skills relevant to the environment in formulating approaches ideal for health production at different household structure and community levels to improve maternal and child health programs in Nigeria and Africa.

\section{References}

Abate, K. H., \& Belachew, T. (2017). Women's autonomy and men's involvement in child care and feeding as predictors of infant and young child anthropometric indices in coffee farming households of Jimma Zone, South West of Ethiopia. Public Library of Science ONE, 12, e0172885. doi:10.1371/journal.pone.0172885

Abdulkadir, M. B., \& Abdulkadir, Z. A. (2016). A cross-sectional survey of parental care-seeking behavior for febrile illness among under-five children in Nigeria Alexandria Journal of Medicine, 53, 85-91.

Adebami, O. J., Oyedeji, G. A., Owa, J. A., \& Oyelami, O. A. (2007). Maternal factors in the etiology of fetal malnutrition in Nigeria. Pediatrics International, 4, 150-155.

Akinyemi, J. O., Adedini, S. A., \& Odimegwu, C.O. (2017). Individual v. community-level measures of women's decision-making involvement and child survival in Nigeria. South Africa Journal of Child Health, 11, 26-32.

Akinyemi, J. O., Chisumpa, V. H., \& Odimegwu, C. O. (2016). Household structure, maternal characteristics and childhood mortality in rural sub-Saharan Africa. Rural and Remote Health, 16, 3737.

Albert, I. O., Awe, T., Hearault, G. \& Omitoogun, W. (1995). Informal channels for conflict resolution in Ibadan Nigeria. Ibadan, Nigeria: French Institute for Research in Africa.

Amos, P. M. (2013). Parenting and culture: Evidence from some African communities. In M. L. Seidlde-Moura (Ed.), Parenting in South American and African contexts (pp. 65-77). London, United Kingdom: Intech Open Science. doi:10.5772/56967 
Asindi, A. A., Young, M., Etuk, I., \& Udo, J. J. (1993). Brutality to twins in Southern Nigeria: What is the existing situation? West African journal of Medicine, 12, 148-152.

Azuh, D., Fayomi, O. \& Ajayi, L. (2015) Socio-cultural factors of gender roles in women's health-care utilization in Southwest Nigeria. Open Journal of Social Sciences, 3, 105-117.

Banke-Thomas, O. E., Banke-Thomas, A. O., \& Ameh, C. A. (2017). Factors influencing Utilisation of maternal health services by adolescent mothers in Low-and middle-income countries: A systematic review. BioMed Central Pregnancy and Childbirth, 17, 65. doi:10.1186/s12884017-1246-3

Bascom, W. (1969). The Yoruba of Southwestern Nigeria. New York, NY: Holt Rinehart and Winston, Inc.

Berman, P., Kendall, C., \& Bhattacharyya, K. (1994). The household production of health: Integrating social science perspectives on micro-level health determinants. Social Science and Medicine, 38, 205-215.

Bernardi, F., Harkonen, J., Boertien, D., Rydell, L. A., Bastaits, K., \& Mortelmans, D. (2013). Effects of family forms and dynamics on children's well-being and life chances: Literature review. Families and Societies, Working Paper Series, 4.

Bledsoe, C., \& Isiugo-Abanihe, U. (1989). Strategies of child fosterage among Mende grannies in Sierra Leone. In R. Lesthaeghe (Eds.), Reproduction and social organization in Sub Saharan Africa. Berkeley, CA: University of California Press.

Bloom, B., \& Dawson, D. (1991). Family structure and child health. American Journal of Public Health, 81, 1526-1528.

Braun, V., \& Clarke, V. (2006). Using thematic analysis in psychology. Qualitative Research Psychology, 3, 77-101.

Brieger, W. R., Watts, S. J., \& Yacoob, M. (1989). Guineaworm: An in-depth study of what happens to mothers, families and communities. Social Science and Medicine, 29, 1043-1049.

Brown, A. E. (1998). The structural, cultural and institutional constraints to improved health and nutrition in southwest Nigeria (Doctoral dissertation). University of Florida, Gainesville, FL.

Centre for Public Legal Education Alberta. (2014). Child custody and parenting. Retrieved from https://www.cplea.ca/wp-content/uploads/2015/12/ChildCustodyandParenting.pdf

Cherlin, A. J. (1992). Marriage, divorce, remarriage. Cambridge, MA: Harvard University Press.

Cornish, F., Gillespie, A., \& Zittoun, T. (2014). Collaborative analysis of qualitative data. In U. Flick (Ed.), The SAGE handbook of qualitative data analysis (pp. 79-93). London, United Kingdom: Sage Publications.

Dawson, D. (1991). Family structure and children's health and well-being: data from the National Health Interview Survey on child health. Journal of Marriage and Family, 53, 573-584.

DeLoache, J., \& Gottlieb, A. (2000). A world of babies: Imagined childcare guilds for seven societies. Cambridge, United Kingdom: Cambridge University Press.

Design Council. (2013). Child health and wellbeing: The early years. Retrieved from https://www.designcouncil.org.uk/sites/default/files/asset/document/ 
Ehiri, J. E., Azubuike, M. C., Ubbaonu, C. N., Anyanwu, E. C., Ibe, K. M., \& Ogbonna, M. O. (2001). Critical control points of complementary food preparation and handling in eastern Nigeria. Bull World Health Organization. 79, 423-433.

European Commission. (2013). Investing in children: Breaking the cycle of disadvantage (Commission Recommendation 2013/112/EU). Brussels, Belgium: European Commission. Retrieved from http://eurlex.europa.eu/LexUriServ/LexUriServ.do?uri=OJ:L:2013:059:0005:0016:EN:PDF

Every Woman Every Child. (2015). The global strategy for women's, children's and adolescents' health (2016-2030). Retrieved from http://www.who.int/entity/life-course/partners/globalstrategy/ewec-globalstrategyreport-200915.pdf?ua=1

Ewhrudjakpor, C. (2008). Cultural factors blocking the utilization of orthodox medicine: A case study of Warri area in Delta State of Nigeria. Review of Sociology, 14, 103-119. doi:10.1556/RevSoc.14.2008.6

Ezeh, O. K., Agho, K. E., Dibley, M. J., Hall, J., \& Nicholas, A. (2014). Determinants of neonatal mortality in Nigeria: Evidence from the 2008 demographic and health survey. BioMed Central Public Health, 14, 521. doi:10.1186/1471-2458-14-521

Federal Ministry of Health. (2011). Saving newborn lives in Nigeria: Newborn health in the context of the Integrated Maternal, Newborn and Child Health Strategy (2nd edition). Abuja, Nigeria: Federal Ministry of Health, Save the Children, and Jhpiego. Retrieved from countdown2030.org/documents/countdown-news/nigeria-full-report.pdf

Fereday, J., \& Muir-Cochrane, E. (2006). Demonstrating rigor using thematic analysis: A hybrid approach of inductive and deductive coding and theme development. International Journal of Qualitative Methods; 5, 80-92.

Green, E. C., \& Murphy, E. (2002) Health belief model. In W. C. Cockerham, R. Dingwall \& S. R. Quah (Eds.), Wiley Blackwell encyclopaedia of health, illness, behavior, and society (pp. 766769). Malden, MA: Wiley-Blackwell. Retrieved from http://onlinelibrary.wiley.com/doi/10.1002/9781118410868.wbehibs410/full

Himmelweit, S., Santos, C, Sevilla, A., \& Sofer, C. (2013). Sharing of resources within the family and the economics of household decision-making. Journal of Marriage and Family, 75, 625-639.

Hong, R., Banta, J. E. \& Betancourt, J. A. (2006). Relationship between household wealth inequality and chronic childhood under-nutrition in Bangladesh. International Journal for Equity in Health. 5, 1-25.

Johnson, R. B., Onwuegbuzie, A. J., \& Turner, L. A. (2007). Toward a definition of mixed methods research. Journal of Mixed Methods Research, 1, 112-133.

Lawoyin, T. O. (2001). Risk factors for infant mortality in a rural community in Nigeria. The Journal of the Royal Society for the Promotion of Health, 121, 114-118.

Liu, L., Oza, S., Hogan, D., Perin, J., Rudan, I., Lawn, J. E., . . Black, R. E. (2015). Global, regional, and national causes of child mortality in $2000 \pm 13$, with projections to inform post-2015 priorities: An updated systematic analysis. The Lancet, 385, 430-440.

Marchant, T. (2013). Maternal and newborn health care: Baseline findings from Gombe State, Nigeria: Interactions between families and frontline workers (their frequency, quality, and equity), and coverage of interventions for mothers and newborns (Project report). London, 
United Kingdom: London School of Hygiene and Tropical Medicine. Retrieved from http://researchonline.lshtm.ac.uk/1126638/

McLain, C. (1989). Women as healers: Cross cultural perspectives. Princeton, NJ: Rutgers University Press.

National Population Commission. (2000). Nigeria demographic and health survey 1999. Calverton, MD: National Population Commission and ORC/Macro.

National Population Commission \& ICF International. (2014). Nigeria demographic and health survey (NDHS) 2013. Abuja, Nigeria, and Rockville, MD: Authors.

Nordberg, E., Kimani, V., \& Diwan, V. (2000). Household survey of injuries in a Kenyan district. East African Medical Journal77, 240-224.

Ogunlesi, T. A., \& Ogunlesi, F. B. (2012). Family socio-demographic factors and maternal obstetric factors influencing appropriate health-care seeking behaviours for newborn jaundice in Sagamu, Nigeria. Maternal and Child Health Journal, 16, 677-684.

Ogunlesi, T. A., \& Olanrewaju, D. M. (2010). Socio-demographic factors and appropriate health careseeking behavior for childhood illnesses. Journal of Tropical Pediatrics, 56, 379-385.

Olaogun, A. A., Brieger W. R., Ayoola, A. B., Obianjuwa P. O., \& Adebayo, S. O. (2005). Motherfather concordance on treatment choices in the care of sick children under five years of age in Osun State, Nigeria. International Quarterly of Community Health Education, 25, 283-293.

Olson, K. B. (1994). The household production of health and women's work: New directions in medical anthropology and households research. Arizona Anthropologist, 11, 139-155.

Orubuloye, I. O., Caldwell, J. C., Caldwell, P., \& Bledsoe, C. H. (1991). The impact of family and budget structure on health treatment in Nigeria. Health Transition Review. 1, 189-210.

Oyewumi, O. (1997). The invention of women: Making an African sense of western gender discourses. Minneapolis, MN: University of Minnesota Press.

Pan American Health Organization. (1997). Workshop on gender, health and development: Facilitator's guide. Washington, DC: Author.

Ponthieux, S. (2017). Intra-household pooling and sharing of resources: a tentative "modified" equivalised income. In A. B. Atkinson, A.-C. Guio, \& E. Marlier (Eds.), monitoring social inclusion in Europe (pp. 175-188). Luxembourg, Luxembourg: Publications Office of the European Union.

Russell, M. (2004). Understanding Black households in Southern Africa: The African kinship and Western nuclear family systems (CSSR Working Paper No. 67). Cape Town, South Africa: Centre for Social Science Research, University of Cape Town. Retrieved from http://www.uct.ac.za/depts/cssr/pubs.html. Accessed on 21/04/2017

Salami, K. K., Brieger, W. R., \& Olutayo, L. (2003). Stress and coping among mothers of twins in rural Southwestern Nigeria. Twin Research, 6, 55-61.

Salami, K. K., Dumbili, E., \& Ezeah, P. (2013). Determinants of maternal and child healthcare service utilization among recently pregnant mothers in Ubulu-Okiti, Delta State Nigeria. International Journal of Sociology of the Family, 3, 115-127. 
Sanglimsuwan, K. (2012). Using household models to understand environmental health outcomes in developing countries. International Journal of Behavioral Science, 7, 99-108.

Sankar, V., Batra, P., Saroha, M., \& Sadiza, J. (2017). Parental satisfaction in the traditional system of neonatal intensive care unit services in a public sector hospital in North India. South Africa Journal of Child Health. 11, 54-57. doi:10.7196/SAJCH.2017.v11i1.1253

Seekings, J. (2003). Households and families in Southern Africa: Introduction to the special issue. Social Dynamics, 29, 1-4.

Smith-Greenaway, E. (2013). Maternal reading skills and child mortality in Nigeria: A reassessment of why education matters. Demography. 50, 1551-1561.

Spencer, L., Ritchie, J., \& O’Connor. (2003) Analysis: Practices, principles, and processes. In J. Ritchie \& J. Lewis (Eds.), Qualitative research practice: A guide for social science students and researchers (pp. 199-218). London, United Kingdom: Sage.

The Partnership for Maternal, Newborn, and Child Health. (2006) Opportunities for Africa's newborns: Practical data, policy and programmatic support for newborn care in Africa (J. Lawn \& K. Kerber, Eds.). Geneva, Switzerland: Author. Retrieved from http://www.who.int/pmnch/media/publications/africanewborns

Turon, H. (2016). Home production of childcare and labour supply decisions in a collective household model (Doctoral dissertation). Department of Economics, University of Bristol, Bristol, United Kingdom. Retrieved from http://www.maccalm.org/wpcontent/uploads/2017/01/hhjan16.pdf

United Nations Children's Fund. (2013). Case studies on UNICEF programming in child's protection. New York, NY: Author.

Wacira, D. G., Hill, J., McCall, P. J., \& Kroeger, A. (2007). Delivery of insecticide-treated net services through employer and community-based approaches in Kenya. Tropical Medicine and International health, 12, 140-149.

Watson, W. J., \& Wareham, A. K. (1963). West African Secondary School atlas. Lagos, Nigeria: Thomas Nelson and Sons.

Weiss, H., Caspe, M., \& Lopez, M. E. (2006). Family involvement makes a difference. Harvard Family Research Project, 1, 1-8.

White, D., Dynes, M., Rubardt, M., Sissoko, K., \& Stephenson, R. (2013). The influence of intrafamilial power on maternal health care in Mali: Perspectives of Women, Men and Mothersin-Law. International Perspectives on Sexual and Reproductive Health, 39, 58-68. 
The Journal of Social, Behavioral, and Health Sciences is an open-access, peer-reviewed, online interdisciplinary journal focusing on research findings that address contemporary national and international issues. Its objectives are to (a) encourage dialogue between scholars and practitioners in the social, behavioral, and health sciences that fosters the integration of research with practice; (b) promote innovative models of interdisciplinary collaboration among the social, behavioral, and health sciences that address complex social problems; and (c) inform the relationship between practice and research in the social, behavioral, and health sciences.

Walden University Publishing: http://www.publishing.waldenu.edu 